\title{
Culture-adapted Plasmodium falciparum isolates from UK travellers: in vitro drug sensitivity, clonality and drug resistance markers
}

Donelly A van Schalkwyk ${ }^{1 \dagger}$, Rebekah Burrow ${ }^{1 \dagger}$, Gisela Henriques ${ }^{1}$, Nahla B Gadalla ${ }^{1}$, Khalid B Beshir ${ }^{1}$, Christian Hasford ${ }^{2}$, Stephen G Wright ${ }^{3}$, Xavier C Ding ${ }^{4}$, Peter L Chiodini ${ }^{3}$ and Colin J Sutherland ${ }^{1,3^{*}}$

\begin{abstract}
Background: The screening of lead compounds against in vitro parasite cultures is an essential step in the development of novel anti-malarial drugs, but currently relies on laboratory parasite lines established in vitro during the last century. This study sought to establish in continuous culture a series of recent Plasmodium falciparum isolates to represent the current parasite populations in Africa, all of which are now exposed to artemisinin combination therapy.
\end{abstract}

Methods: Pre-treatment P. falciparum isolates were obtained in EDTA, and placed into continuous culture after sampling of DNA. One post-treatment blood sample was also collected for each donor to monitor parasite clonality during clearance in vivo. $\mathrm{IC}_{50}$ estimates were obtained for 11 anti-malarial compounds for each established parasite line, clonal multiplicity measured in vivo and in vitro, and polymorphic sites implicated in parasite sensitivity to drugs were investigated at the pfmdr1, pfcrt, pfdhfr, pfdhps and pfap2mu loci before and after treatment, and in the cultured lines.

Results: Plasmodium falciparum isolates from seven malaria patients with recent travel to three West African and two East African countries were successfully established in long-term culture. One of these, HL1211, was from a patient with recrudescent parasitaemia 14 days after a full course of artemether-lumefantrine. All established culture lines were shown to be polyclonal, reflecting the in vivo isolates from which they were derived, and at least two lines reliably produce gametocytes in vitro. Two lines displayed high chloroquine $\mathrm{IC}_{50}$ estimates, and carried the CVIET haplotype at codons 72-76, whereas the remaining five lines carried the CVMNK haplotype and were sensitive in vitro. All were sensitive to the endoperoxides dihydroartemisinin and $\mathrm{OZ277}$, but $I_{50}$ estimates for lumefantrine varied, with the least sensitive parasites carrying pfmdr1 alleles encoding Asn at codon 86.

Conclusions: This study describes the establishment in continuous culture, in vitro drug sensitivity testing and molecular characterization of a series of multiclonal $P$. falciparum isolates taken directly from UK malaria patients following recent travel to various malaria-endemic countries in Africa. These " $\mathrm{HL}$ " isolates are available as an open resource for studies of drug response, antigenic diversity and other aspects of parasite biology.

\footnotetext{
* Correspondence: colin.sutherland@lshtm.ac.uk

${ }^{\dagger}$ Equal contributors

${ }^{1}$ Faculty of Infectious and Tropical Diseases, London School of Hygiene and

Tropical Medicine, Keppel Street, London WC1E 7HT, UK

${ }^{3}$ Department of Clinical Parasitology, Hospital for Tropical Diseases, Mortimer

Market Centre, Capper Street, London WC1E 6JB, UK

Full list of author information is available at the end of the article
} 


\section{Background}

There are currently six species of the genus Plasmodium known to infect humans: Plasmodium falciparum, Plasmodium vivax, Plasmodium ovale curtisi, Plasmodium ovale wallikeri, Plasmodium malariae and Plasmodium knowlesi $[1,2]$. Of these, P. falciparum is the species responsible for most of the mortality and morbidity associated with the disease and it is during the asexual intraerythrocytic stages that most of the symptoms of malaria are manifest. Studies into many aspects of human malaria parasite biology were greatly advanced by the development of a method to culture asexual blood stages of P. falciparum in vitro in 1976 [3]. Since then, several parasite strains and clones have been cultivated from varying geographical regions, allowing researchers to explore differences in parasite phenotypes as diverse as immune evasion in mosquitoes [4] and red cell invasion [5] to the development of drug resistance [6,7]. However, the most widely studied in vitro parasite strains or clones have been in use for more than two decades (Table 1) and therefore pre-date the era of widespread artemisinin-based combination therapy (ACT) implementation. In addition, many of these parasite lines originate from Asia or the Americas (Table 1). However, it is in Africa where the majority of deaths from malaria are reported, and the greatest transmission intensity occurs [8]. Moreover, information about the infection from which the parasites lines were isolated (i e, possible parasite drug exposure from prophylaxis, patient travel histories, etc.) is not easy to access, if at all available.

Since 2001 the World Health Organization (WHO) has recommended ACT as first-line treatment for uncomplicated $P$. falciparum malaria infections [26]. ACT involves pairing an artemisinin derivative, with its short elimination half-life, with a longer-lasting antimalarial partner drug (e g, artemether-lumefantrine, dihydroartemisinin-piperaquine, etc.). This approach to treatment has been highly successful for several years in areas where drug resistance to chloroquine or sulphadoxine-pyrimethamine had been widespread [27]. However, an increasing number of infections exhibiting reduced sensitivity to artemisinin in vivo are being observed in areas of western Cambodia, Thailand and recently southern Myanmar [28-32]. This has been attributed to a delayed clearance phenotype with recent evidence suggesting that parasites have developed a mechanism that allows them to remain dormant in the ring stage of their life cycle in order to evade the toxic effects of the short half-life artemisinin derivative [33,34]. This developing altered phenotype highlights a need to update in vitro parasite lines in order to study parasites whose behaviour reflect the current antimalarial exposure patterns.

Table 1 List of Plasmodium falciparum strains/clones in current widespread use for in vitro studies

\begin{tabular}{|c|c|c|c|c|}
\hline Strain/Clone ${ }^{\S}$ & Origin & Region & Year reported* & Reference \\
\hline \multicolumn{5}{|l|}{ Chloroquine sensitive } \\
\hline NF-54 & Netherlands & Europe & 1981 & {$[9,10]$} \\
\hline 3D7 (cloned from NF-54) & Netherlands & Europe & 1987 & [11] \\
\hline D10 (cloned from FC27) & Papua New Guinea & Oceania & 1983 & {$[12]$} \\
\hline HB3 (cloned from Honduras I/CDC) & Honduras & Central America & 1984 & [13] \\
\hline D6 (cloned from Sierra Leone I/CDC) & Sierra Leone & Africa & 1988 & [14] \\
\hline T9-96 (cloned from T9) & Thailand & Asia & 1981 & {$[15,16]$} \\
\hline GB4 (cloned from Ghana III/CDC) & Ghana & Africa & 2003 & {$[17]$} \\
\hline ITG2F6 (cloned from Ituxi 084) & Brazil & South America & 1979 & [18] \\
\hline \multicolumn{5}{|l|}{ Chloroquine resistant } \\
\hline K1 & Thailand & Asia & 1981 & {$[19]$} \\
\hline FCR3 & The Gambia & Africa & 1981 & {$[20]$} \\
\hline W2 (cloned from Indo III/CDC) & Indochina & Asia & 1988 & [14] \\
\hline W2mef (derived from W2) & Indochina & Asia & 1988 & [21] \\
\hline Dd2 (cloned from W2mef) & Indochina & Asia & 1988 & {$[22]$} \\
\hline 7G8 (cloned from IMTM22) & Brazil & South America & 1984 & {$[23]$} \\
\hline V1/S (cloned from V1) & Vietnam & Asia & 1990 & [24] \\
\hline Malayan Camp & Malaya & Asia & 1965 & {$[25]$} \\
\hline
\end{tabular}

${ }^{5}$ This list is not meant to reflect an exhaustive reference of all the parasite lines in use world-wide and it excludes the multiple progeny of the HB3 $\times$ Dd2 genetic cross or the $7 \mathrm{G} 8 \times \mathrm{GB} 4$ genetic cross. Instead, it represents a list of parasites that predominate in the literature still today in several genetic and drug sensitivity studies.

*These are the earliest literature reports for the parasite lines/clones listed so the actual date of establishment in culture pre-dates these references in each case. 
There are currently no validated molecular markers for parasites with reduced susceptibility to artemisinin, but persistent parasitaemia after treatment with artemetherlumefantrine has been associated with particular alleles of pfmdr1 in vivo [35]. Recent published data from studies of artemisinin resistance in the rodent parasite Plasmodium chabaudi has identified a new candidate locus, pcap $2 m u$, encoding the clathrin-associated $\mu$ adaptor protein 2 [36]. These authors described potentially important sequence diversity in the $P$. falciparum homologue, pfap2mu (PF3D7_1218300), between codons 146 and 437 , in a series of clinical isolates.

The aim of this study was to establish a fully characterized panel of recent $P$. falciparum isolates, adapted to grow under standard in vitro culture conditions, for studies of sensitivity to both established and investigational anti-malarial drugs. This small series of newly cultureadapted $P$. falciparum isolates, together with relevant genotyping analysis at loci of interest and drug response phenotypes, has been made available as a resource for researchers wishing to work in vitro with African parasites from the current ACT era.

\section{Methods}

\section{Patient sample acquisition}

Voluntary consent and travel history was obtained from patients presenting with malaria to the Hospital for Tropical Diseases, London (HTD), or the Accident and Emergency Department of University College London Hospitals (UCLH). A venous blood sample was obtained in a $4 \mathrm{~mL}$ Vacutainer tube containing EDTA (BD, Oxfordshire, UK). A few drops of blood were removed to prepare thick and thin blood smears in order to confirm diagnosis and to establish parasitaemia. A $200 \mu \mathrm{L}$ aliquot of whole blood was removed for DNA extraction for use in later genotyping assays. The remaining sample was then used for the laboratory adaptation of the malaria parasites in the malaria culture laboratories, London School of Hygiene \& Tropical Medicine (LSHTM). All patient identifiers were removed and a code assigned to each parasite sample. Approval for the study was obtained from the Research Ethics Committee of the University College London Hospitals (Application number: 07/Q0505/60). All seven patients described herein were managed as in-patients, with fully observed antimalarial treatment. Those treated with AL received the standard dosage of Riamet@ as recommended by the manufacturer (Novartis Pharmaceuticals UK Ltd), which comprises six doses of four tablets each, taken over 60 hours. Each tablet contains $20 \mathrm{mg}$ artemether and $120 \mathrm{mg}$ lumefantrine.

\section{General reagents and compounds for growth inhibition studies}

Albumax II and gentamicin sulphate were purchased from Invitrogen (Carlsbad, CA, USA). HEPES, RPMI 1640, human $\mathrm{AB}$ serum, hypoxanthine, L-glutamine and Dglucose were purchased from Sigma-Aldrich (St Louis, MO, USA). Anti-malarial compounds/drugs used in this study were supplied by the Medicines for Malaria Venture (MMV, Geneva, Switzerland). Primary stock solutions for all compounds, except chloroquine, were first made by dissolution in dimethyl sulphoxide (DMSO). Subsequent dilutions were made in complete RPMI growth media such that the amount of DMSO present in the test concentration range was non-toxic to parasites. Chloroquine primary stocks were made by dissolution in deionized water (Millipore, Watford, UK).

\section{Laboratory adaptation and parasite culture}

The whole blood sample obtained from the patients was first washed twice in RPMI growth media in order to separate the red cells from the plasma. Briefly, the whole blood was suspended in $6 \mathrm{~mL}$ of RPMI media and centrifuged at $2,000 \times \mathrm{g}$ for $10 \mathrm{~min}$. The supernatant and buffy coat were then removed and the red cell pellet was suspended in approximately $8 \mathrm{~mL}$ of RPMI before a second centrifugation step as described above. After removing the supernatant the parasitized red cells were resuspended in complete medium (CM) for culture adaptation. For the first isolate obtained (HL1204) this was composed of RPMI 1640 growth medium supplemented with $10 \%$ (v/v) human $\mathrm{AB}$ serum, $25 \mathrm{mg} / \mathrm{L}$ gentamicin, $147 \mu \mathrm{M}$ hypoxanthine, $25 \mathrm{mM}$ HEPES, and $25 \mathrm{mM} \mathrm{Na}_{2} \mathrm{HCO}_{3}$. For all subsequent isolate adaptation and routine parasite cultivation the amount of human serum added was reduced to $2 \%(\mathrm{v} / \mathrm{v})$ and the CM further supplemented with $5 \mathrm{~g} / \mathrm{L}$ Albumax II, $10 \mathrm{mM}$ D-glucose and $2 \mathrm{mM}$ L-glutamine. The parasites were maintained in continuous culture with shaking. The parasites were stored in a sealed flask incubated at $37^{\circ} \mathrm{C}$ under a gas mixture of $93 \% \mathrm{~N}_{2}, 4 \% \mathrm{CO}_{2}$ and $3 \% \mathrm{O}_{2}$. As the parasitaemia increased the parasites were diluted in human $\mathrm{A}^{+}$blood (National Health Blood \& Transplant, UK) to maintain a parasitaemia $<4 \%$ and a haematocrit of $4 \%$.

Early passage stabilates of all seven lines have been deposited at the European Malaria Reagent Repository [37] and are available for general research use.

\section{Anti-plasmodial activity assays}

Growth curves were initiated on ring stage parasites with a final parasitaemia of $0.5 \%$ and a haematocrit of $2 \%$ in a $200 \mu \mathrm{L}$ volume within 96 -well microtitre plates. Serial twoor three-fold drug dilutions were first performed across the plate in duplicate wells and the parasites added thereafter. The plate was incubated for $48 \mathrm{hrs}$ at $37^{\circ} \mathrm{C}$ and parasite growth was measured using the PicoGreen method [38]. Briefly, PicoGreen (Invitrogen, P7581) was diluted 1:200 into a lysis buffer made up of $20 \mathrm{mM}$ Tris, $5 \mathrm{mM}$ EDTA, $0.008 \%(\mathrm{w} / \mathrm{v})$ saponin and $0.08 \%$ Triton X-100 (pH 7.5). Thereafter, $50 \mu \mathrm{L}$ of this solution was pipetted into each 
well of a duplicate 96-well plate. Then $100 \mu \mathrm{L}$ of the resuspended parasite solution was transferred from the original growth assay plate into the Picogreen plate and was mixed well. This plate was kept in the dark for at least $10 \mathrm{~min}$ and was read in a Spectramax M3 microplate reader (Molecular Devices, Berkshire, UK) at an excitation wavelength of $485 \mathrm{~nm}$ and an emission wavelength of $538 \mathrm{~nm}$.

\section{DNA isolation}

Parasite genomic DNA was extracted from $200 \mu \mathrm{L}$ of whole blood (for patient-derived samples) or $200 \mu \mathrm{L}$ of packed red cells (for culture-adapted parasites) using the QIAamp DNA Blood Mini Kit (Qiagen, UK) as per the manufacturer's instructions. The DNA was stored at $-80^{\circ} \mathrm{C}$.

\section{Estimating multiplicity of infection}

The $P$. falciparum isolates were assessed for multiplicity of infection (MOI) by nested PCR analysis of $m s p 1$ block 2 (K1, MAD20, RO33) and msp2 block 3 (FC27, 3D7/IC). These alleles are characterized by conserved regions flanked by repeat sequences of variable length; size variation within the alleles can be used to discriminate different parasite clones by PCR fragment length polymorphism. Previously designed primer sets were used but with modified cycling conditions [39], as follows. Nest 1 amplifications were performed in $25 \mu \mathrm{L}$ reaction mixture containing $5 \mu \mathrm{L}$ DNA, $\mathrm{NH}_{4}$ buffer, $4 \mathrm{mM} \mathrm{MgCl} 2,1 \mathrm{mM}$ deoxynucleotides (dNTPs), $0.2 \mu \mathrm{M}$ forward primer, $0.2 \mu \mathrm{M}$ reverse primer and 1 unit of BIOTAQ ${ }^{\mathrm{m}}$ (Bioline, UK). The cycling conditions were: denaturation at $94^{\circ} \mathrm{C}$ for $3 \mathrm{~min}, 30$ cycles of $94^{\circ} \mathrm{C}$ for $30 \mathrm{sec}, 58^{\circ} \mathrm{C}$ for $1 \mathrm{~min}$ and $68^{\circ} \mathrm{C}$ for $1 \mathrm{~min}$, followed by a final extension of $5 \mathrm{~min}$ at $68^{\circ} \mathrm{C}$.

Nest 2 amplifications were performed in a $25 \mu \mathrm{L}$ reaction mixture containing $1 \mu \mathrm{L}$ of nest 1 product diluted $1 / 10$, $\mathrm{NH}_{4}$ buffer, $4 \mathrm{mM} \mathrm{MgCl}, 1 \mathrm{mM}$ dNTPs, $0.2 \mu \mathrm{M}$ forward primer, $0.2 \mu \mathrm{M}$ reverse primer and 1 unit of BIOTAQ. The cycling conditions were: denaturation at $94^{\circ} \mathrm{C}$ for $3 \mathrm{~min}$, 30 cycles of $94^{\circ} \mathrm{C}$ for $30 \mathrm{sec}, 61^{\circ} \mathrm{C}$ for $1 \mathrm{~min}$ and $72^{\circ} \mathrm{C}$ for $1 \mathrm{~min}$, followed by a final extension of $5 \mathrm{~min}$ at $72^{\circ} \mathrm{C}$.

In order to separate and visualize the amplification products by electrophoresis, $15 \mu \mathrm{L}$ of amplification products mixed with loading buffer was loaded onto $2 \%$ agarose gels in $0.5 \%$ TBE buffer, stained with ethidium bromide (EtBr). The minimum MOI was calculated to be the highest observed number of size variants for either $p f m s p 1$ or $p f m s p 2$ for any sample (Day 0, Day 1, cultureadapted) of an isolate.

\section{Genotyping of drug resistance markers pfort}

The genotype for pfcrt was determined by multiplex real-time qPCR performed in a Rotorgene RG3000 thermocycler (Corbett Research, Australia), in which a small segment around codons $72-76$ was amplified in the presence of three dual-labelled probes complementary to CVMNK (FAM fluorophore), CVIET (JOE fluorophore) and SVMNT (ROX fluorophore) exactly as described previously [40,41]. For data analysis, a threshold for each probe was set manually using the positive and negative controls.

\section{pfmdr1}

Amplification of pfmdr1 for sequencing required two amplicons, as described previously [42], with minor modifications as follows [see Additional file 1]. For fragment 1, the nest $125 \mu \mathrm{L}$ reaction mixture contained $5 \mu \mathrm{L}$ DNA, $\mathrm{NH}_{4}$ buffer, $2 \mathrm{mM} \mathrm{MgCl} 2,1 \mathrm{mM}$ dNTPs, $0.2 \mu \mathrm{M}$ of each primer and 1 unit of BIOTAQ. The cycling conditions were $94^{\circ} \mathrm{C}$ for $3 \mathrm{~min}$ followed by 30 cycles of $94^{\circ} \mathrm{C}$ for $30 \mathrm{sec}, 55^{\circ} \mathrm{C}$ for $30 \mathrm{sec}, 65^{\circ} \mathrm{C}$ for $1 \mathrm{~min}$, and then a final elongation at $65^{\circ} \mathrm{C}$ for $5 \mathrm{~min}$. The nest 2 reaction contained $1 \mu \mathrm{L}$ nest 1 product, primers MDR2/1 and NEWREV1 and other reagents as for the nest 1 reaction. Cycling conditions were $94^{\circ} \mathrm{C}$ for $3 \mathrm{~min}$ followed by 30 cycles of $94^{\circ} \mathrm{C}$ for $30 \mathrm{sec}, 60^{\circ} \mathrm{C}$ for $30 \mathrm{sec}, 65^{\circ} \mathrm{C}$ for $1 \mathrm{~min}$, and then a final elongation at $65^{\circ} \mathrm{C}$ for $5 \mathrm{~min}$. For fragment 2, the nest 1 $25 \mu \mathrm{L}$ reaction mixture contained $5 \mu \mathrm{L}$ DNA, $\mathrm{NH}_{4}$ buffer, $2 \mathrm{mM} \mathrm{MgCl}, 1 \mathrm{mM}$ dNTPs, $0.2 \mu \mathrm{M}$ of each primer and 1 unit of BIOTAQ. The cycling conditions were $94^{\circ} \mathrm{C}$ for 3 min followed by 35 cycles of $94^{\circ} \mathrm{C}$ for $30 \mathrm{sec}, 55^{\circ} \mathrm{C}$ for $30 \mathrm{sec}, 68^{\circ} \mathrm{C}$ for $45 \mathrm{sec}$, and then a final elongation at $68^{\circ} \mathrm{C}$ for $2 \mathrm{~min}$. The nest 2 reaction contained $1 \mu \mathrm{L}$ of nest 1 product, primers newfr2_F and newfr2_N2R and other reagents as for the nest 1 reaction. The cycling conditions were $94^{\circ} \mathrm{C}$ for $3 \mathrm{~min}$ followed by 35 cycles of $94^{\circ} \mathrm{C}$ for $30 \mathrm{sec}, 55^{\circ} \mathrm{C}$ for $30 \mathrm{sec}, 68^{\circ} \mathrm{C}$ for $45 \mathrm{sec}$, and then a final elongation at $68^{\circ} \mathrm{C}$ for $2 \mathrm{~min}$. Amplicons were sequenced using BigDye Terminator v3.1 cycle sequencing kits and analysis on an ABI 3730 sequencer (Applied Biosystems). The sequences were analyzed using Geneious R6 software (Biomatters, New Zealand). Gene copy number for $p f m d r 1$ was determined by real-time qPCR using the DD- $C_{T}$ method, exactly as described previously [35].

\section{pfdhfr}

Amplification of pfdhfr was performed by nested PCR amplification exactly as described elsewhere [43].

\section{pfdhps}

Amplification of pfdhps was performed by nested PCR amplification and partial sequencing using the amplification primers $\mathrm{R} 2$ and $\mathrm{R} /$ described by Pearce et al. [43], with the following modifications. Each $25 \mu \mathrm{L}$ reaction mixture contained $5 \mu \mathrm{L}$ DNA, KCl buffer, $0.2 \mathrm{mM}$ dNTPs, $0.4 \mu \mathrm{M}$ of each primer and 1 unit of BIOTAQ. The cycling conditions were $93^{\circ} \mathrm{C}$ for $5 \mathrm{~min}$ followed by 40 cycles of $93^{\circ} \mathrm{C}$ for $20 \mathrm{sec}, 55^{\circ} \mathrm{C}$ for $30 \mathrm{sec}, 68^{\circ} \mathrm{C}$ for $75 \mathrm{sec}$, and then a final elongation at $68^{\circ} \mathrm{C}$ for $5 \mathrm{~min}$. The nest 2 reaction 
contained $1 \mu \mathrm{L}$ of nest 1 product, $0.4 \mu \mathrm{M}$ each of primers midFWD and midREV [44] and other reagents as for the nest 1 reaction. The cycling conditions were $93^{\circ} \mathrm{C}$ for $5 \mathrm{mi}$ nutes followed by 30 cycles of $93^{\circ} \mathrm{C}$ for $20 \mathrm{sec}, 56^{\circ} \mathrm{C}$ for $30 \mathrm{sec}, 68^{\circ} \mathrm{C}$ for $75 \mathrm{sec}$, and then a final elongation at $72^{\circ} \mathrm{C}$ for $5 \mathrm{~min}$.

\section{pfap2mu}

Three nested fragments of pfap2mu (gene ID PF3D7_1218300) were amplified from a single primary amplicon as described [Hallett RL, Henriques G, Beshir KB, Gadalla NB, Burrow R, van Schalkwyk DA, Sawa P, Bousema T, Sutherland CJ: Sub-microscopic Plasmodium falciparum persisting in Kenyan children immediately after ACT show directional selection at the pfmdr1, pfcrt, $p f u b p-1$ and $p f a p 2 m u$ loci, in preparation.], using primers and conditions provided in the additional file [see Additional file 1]. Each amplification reaction was performed in a total volume of $25 \mu \mathrm{L}$ with the following reaction mixture: $0.2 \mu \mathrm{M}$ of each primer, $4.0 \mathrm{mM} \mathrm{MgCl}_{2}$, $0.4 \mathrm{mM}$ dNTPs and $1 \mathrm{U}$ Bioline Taq polymerase (Bioline, UK). Extracted DNA ( $5 \mu \mathrm{L})$ was added to each first round PCR mixture. One microliter of the first round product was then used as a template in a $25 \mu \mathrm{L}$ nested amplification. The thermal cycle programme for the primary amplification was $94^{\circ} \mathrm{C}$ for $3 \mathrm{~min}$, and 30 cycles of $94^{\circ} \mathrm{C}$ for $30 \mathrm{sec}$, annealing temperature for $30 \mathrm{sec}$ and $68^{\circ} \mathrm{C}$ for $1 \mathrm{~min}$ with a final extension of $68^{\circ} \mathrm{C}$ for $15 \mathrm{~min}$. The second round of PCR consisted of one initial denaturation hold at $94^{\circ} \mathrm{C}$ for $3 \mathrm{~min}$, followed by 40 cycles of $94^{\circ} \mathrm{C}$ for $30 \mathrm{sec}$, annealing temperature for $30 \mathrm{sec}$ and $68^{\circ} \mathrm{C}$ for $45 \mathrm{sec}$ with a final extension of $68^{\circ} \mathrm{C}$ for $10 \mathrm{~min}$.

\section{Sequencing of PCR products}

PCR-amplified products from all loci were purified with Exonuclease I (ExoI) and Thermosensitive Alkaline Phosphatase (AP) enzymes (Fermentas, UK) in order to eliminate non-incorporated dNTPs and primers. The enzymatic purification was carried out in a final volume of $10 \mu \mathrm{L}$ containing $5 \mu \mathrm{L}$ of the PCR product, $3 \mathrm{U}$ ExoI, $1 \mathrm{U}$ AP and $1 \mathrm{X}$ AP reaction buffer, which were incubated for $60 \mathrm{~min}$ at $37^{\circ} \mathrm{C}$ followed by $15 \mathrm{~min}$ at $72^{\circ} \mathrm{C}$ for enzyme denaturation.

The cycle sequencing reactions were carried out using $1 \mu \mathrm{L}$ Exol/AP purified PCR amplicons, $0.5 \mu \mathrm{L}$ BigDye ${ }^{\oplus}$ Terminator v3.1 Cycle Sequencing Kit reaction mix (Applied Biosystems, UK), $0.2 \mu \mathrm{M}$ of each PCR primer, $1.75 \mu \mathrm{L}$ Big Dye Sequencing Buffer (Applied Biosystems) in a total volume of $10 \mu \mathrm{L}$. Single-base extension was performed as follows: one denaturation hold at $96^{\circ} \mathrm{C}$ for $1 \mathrm{~min}$ followed by 25 cycles of $96^{\circ} \mathrm{C}$ for $30 \mathrm{sec}, 50^{\circ} \mathrm{C}$ for $15 \mathrm{sec}$, and $60^{\circ} \mathrm{C}$ for $4 \mathrm{~min}$.

The sequenced reaction fragments were purified using ethanol/sodium acetate precipitation method, where
$3 \mu \mathrm{L} 3$ NaOAc (pH 4.6), $62.5 \mu \mathrm{L}$ 100\% ethanol and $24.5 \mu \mathrm{L}$ of nuclease free water were added to each sample. The samples were mixed by inversion and incubated at $-20^{\circ} \mathrm{C}$ for $25 \mathrm{~min}$. After incubation, samples were centrifuged at $4^{\circ} \mathrm{C}$ at $3000 \mathrm{~g}$ for $30 \mathrm{~min}$. The supernatant was discarded by inversion, $150 \mu \mathrm{L}$ ice cold $70 \%$ ethanol was added and the samples centrifuged at $4^{\circ} \mathrm{C}$ at $3000 \mathrm{~g}$ for $10 \mathrm{~min}$. The supernatant was discarded by inversion and each sample was allowed to dry at room temperature for $30 \mathrm{~min}$. Finally, pellets were resuspended in $10 \mu \mathrm{L} \mathrm{Hi}$ Di formamide. Samples were fractionated on an ABI prism 3730 Genetic Analyzer (Applied Biosystems). Raw sequence data in the form of chromatograms from both sense and antisense primers were edited, aligned and assembled into contigs using Geneious Pro software (version 5.5.3; Biomatters, New Zealand), after resolving potential ambiguities by eye. Genetic polymorphisms were identified by comparing each sequence to that of the 3D7 reference genome.

\section{Statistics}

Plasmodium falciparum sensitivity to anti-malarial compounds in vitro was calculated relative to untreated control wells of the same parasite line by first subtracting the background fluorescence (i e, from parasites exposed to a supralethal $10 \mu \mathrm{M}$ chloroquine concentration) from all the remaining parasite-containing wells. The fluorescence signal from each drug-exposed parasite well was then divided by the average fluorescent signal from drug-free parasite control wells and converted to percentage viability. Viability $v s$ concentration was plotted in SigmaPlot 2000 or Prism v4.02 and curves generated using sigmoidal dose response functions. The $\mathrm{IC}_{50}$ values were then extrapolated from these curves for each drug. Statistical comparisons of the $\mathrm{IC}_{50}$ values were performed using Student's two-tailed t-test for paired or unpaired samples as appropriate.

\section{Results}

Plasmodium spp. parasites were obtained from travellers returning to London from several malaria-endemic regions within Africa, between February and October 2012. Long-term culture was attempted on P. falciparum isolates from seven patients with microscopy-confirmed uncomplicated falciparum malaria, and who gave written informed consent for inclusion in the study. Seven in vitro parasite lines were successfully obtained, and each given a designation of the form HL12XX, for HTD / LSHTM 2012, plus a two-digit serial number. Also receiving HL designations were five non-falciparum parasite isolates (two $P$. vivax, one $P$. ovale curtisi and one $P$. malariae) collected for ex vivo drug sensitivity assays, which will be reported elsewhere. 


\section{Patient travel histories and treatment HL1204 - Kenya}

This isolate was collected from a UK-resident adult male of Kenyan origin who had spent three weeks in Nairobi and coastal Kenya. Symptoms arose two weeks after return to the UK, and persisted for one week before attending HTD with $3.6 \%$ P. falciparum parasitaemia by microscopy. Schizonts and gametocytes were seen. Treatment was with intravenous artesunate due to high parasitaemia and early indicators of organ dysfunction. Parasitaemia estimates at 18,45 and 68 hours were 3.2, 0.0001 and $0.001 \%$, respectively, and the patient was discharged at $\sim 72$ hours on a full course of oral artemether-lumefantrine. The pre-treatment sample was placed into culture within $120 \mathrm{~min}$ of collection. An additional DNA preparation was obtained from the 18-hour sample.

\section{HL1205 - Nigeria}

The donor of this isolate was a UK-resident adult Nigerian woman who spent two weeks in Lagos with her husband. On return to the UK, symptoms arose, and the patient reported taking two tablets of Nivaquine (probably $200 \mathrm{mg}$ chloroquine-sulphate) four days before presenting to UCLH with $3.2 \%$ peripheral parasitaemia, schizonts being present in the blood films. The patient received two doses of intravenous artesunate and, once improved, switched to a full oral course of artemether-lumefantrine. (The patient's husband was also diagnosed with falciparum malaria, hospitalized and treated at the same time as his wife.) Estimates of peripheral parasitaemia at 15, 36 and $\sim 50$ hours were $0.38,0.0001 \%$ and negative, respectively. There was a 16-hour delay between collection of the pre-treatment sample and initiation of culture. An additional DNA preparation was obtained from the 15-hour sample.

\section{HL1209 - South Sudan}

A UK-born UK resident who frequently travels to Africa, and with a previous history of three treated malaria infections, presented six days after return from a six-week trip to South Sudan. Microscopy confirmed $1.6 \%$ peripheral $P$. falciparum parasitaemia with schizonts present, and the patient was started on intravenous artesunate. Estimates of parasitaemia at 13, 37 and 57 hours were 3.2, 0.005\% and negative, respectively. The patient was discharged on a full oral course of artemether-lumefantrine. There was a nine-hour delay between collection of the pre-treatment sample (at 00:45) and its processing for continuous culture. An additional DNA preparation was obtained from the 13-hour sample.

\section{HL1210 - Ghana}

This isolate was donated by an Indian-born young adult male, resident in Singapore but studying in the UK. The subject returned to the UK following a two-week trip to
Ghana for a college project, and reported purchasing a course of anti-malarial chemoprophylaxis from a high street pharmacy in the UK before departure. Described as "two large tablets taken weekly and two small tablets taken daily", this was almost certainly a course of chloroquine-proguanil, which does not require a prescription in the UK, but is no longer considered appropriate chemoprophylaxis for sub-Saharan Africa [41]. The patient stated that the course was not completed. He was well enough to attend a one-day international cricket match four days after returning to the UK, but developed symptoms the following day, which were managed with analgesics for three days. On the fourth day of symptoms, a peripheral $P$. falciparum parasitaemia of $0.3 \%$ was diagnosed at HTD, and the patient admitted to UCLH on oral artemether-lumefantrine. At 15 hours, parasitaemia had fallen to $0.05 \%$, and the patient had improved sufficiently to recall the score in the cricket match. At 40 hours, parasitaemia was $0.0001 \%$ and the patient was discharged. The pre-treatment sample was collected at 17:45, and sat at ambient temperature in the laboratory overnight, before being placed into culture at $~ 10: 00$ next morning. An additional DNA preparation was obtained from the 15hour sample.

\section{HL1211 - Ghana}

Blood samples from this patient, a young British adult male, were referred to HTD by an outside hospital in London, as a suspected case of artemether-lumefantrine treatment failure. The patient gave retrospective written signed consent to his physician for inclusion of parasitepositive samples in the study. Having presented with a $P$. falciparum parasitaemia of $0.03 \%$, the patient was treated with oral artemether-lumefantrine, although it is unknown whether this was administered with fatty food, as recommended. At six hours, parasitaemia had increased to $4.2 \%$, but fallen to $1.1 \%$ by 24 hours, and $0.001 \%$ by 48 hours. The patient was discharged following a negative blood film at 72 hours.

Fourteen days later, symptoms recurred, and P. falciparum parasitaemia of $0.7 \%$ was confirmed by the on-call microscopist at HTD, at 21:58 on a Sunday night. This EDTA vacutainer sample spent 60 hours at $4^{\circ} \mathrm{C}$ before being placed into continuous culture. The patient was treated with oral atovaquone-proguanil, and parasitaemia fell to 0.4 and then $0.07 \%$, before eventual parasite clearance and a full recovery. An additional DNA preparation was obtained from the sample with $0.4 \%$ parasitaemia.

\section{HL1212 - Nigeria}

Blood samples for this isolate were referred to HTD from a hospital outside London because the patient, an adult UK resident female who recently travelled to Nigeria, carried an unusual hyper-gametocytaemia, in addition to 
asexual parasitaemia of approximately $1.5 \%$. The patient's immediate family gave written permission for any viable malaria parasites to be placed in culture for research. No post-treatment sample was available for analysis for this patient.

\section{HL1214 - Burkina Faso}

The donor of this isolate was a South African born adult female, a UK resident, who had spent three days in Burkina Faso on business. Malaria symptoms began 11 days after returning to London, and a blood sample taken at $21: 46$ on the 12 th day was found to have $1.0 \%$ $P$. falciparum parasitaemia. The patient was treated with oral artemether-lumefantrine, and a single followup blood sample taken at 36 hours; this was negative and the patient was discharged to complete her oral chemotherapy at home. The pre-treatment blood sample was placed into continuous culture approximately 12 hours after collection. An additional DNA preparation was obtained from the 36-hour (microscopy negative) sample.

\section{Establishment of cultures and gametocyte production}

The first parasite isolate (HL1204) was placed directly into standard growth medium of RPMI supplemented with 10\% human $\mathrm{AB}$ serum. However, these parasites initially experienced a large decline in parasitaemia and took several weeks to recover their growth in culture. When the second isolate was received, the Methods for Malaria Research protocol was adopted [45] which combines a reduced amount of human serum (2\%) with $0.5 \mathrm{~g} / \mathrm{L}$ of Albumax II in the RPMI growth medium (see Methods for full details). In this growth medium, most parasite cultures adapted to in vitro culture without a marked decline in parasite growth. HL1204 was later also cultured in this alternative RPMI growth media. All the $P$. falciparum parasites received were successfully adapted to in vitro parasite growth after periods of time varying from 12 days to nine weeks, and initial stocks were frozen within approximately two weeks. Isolates were maintained in culture for no longer than 12 weeks after thawing in order to minimize the effects on parasite populations of genetic drift and loss of chromosome fragments.

It was noted that the first isolate, HL1204 from Kenya, produced gametocytes in culture spontaneously when the parasitaemia increased beyond 2\%. Similarly, HL1205 was observed to produce scanty gametocytes at high parasitaemia in vitro. The gametocyte-producing property of the HL1204 isolate is currently being used to produce sexual parasite forms for transmission studies in mosquitoes (data not shown). Isolate HL1212 was obtained from a patient with peripheral hypergametocytaemia at the time of treatment, but after a few weeks of in vitro cultivation, there was no evidence of this phenotype persisting, as gametocytes were not observed in significant numbers in the established cultures under standard conditions.

\section{Multiplicity of infection (Mol)}

Nested PCR amplification of the P. falciparum merozoite surface protein 1 (pfmsp1) or 2 (pfmsp2) locus was used to estimate the minimum number of clones present in the isolates as reported previously $[39,46]$. DNA samples for each isolate were obtained before drug treatment of the patients (Day 0) and one-day after drug treatment (Day 1) for comparison. A further sample was taken when the parasites were successfully adapted to grow in culture in order to examine whether the population of clones in the isolates had changed from the time of presentation at Day 0 .

Aside from HL1214, the isolates were shown to contain at least four to six clones (Table 2). For the HL1214 isolate from Burkina Faso, a minimum multiplicity of two clones was estimated before drug treatment (Day 0) and both were found to persist into the culture adapted line. Similarly, three other isolates showed the same number of clones persisting into culture as those observed at presentation; HL1205 (four clones), HL1209 (six clones) and HL1210 (four clones). However, for isolates HL1204 and HL1212 there were fewer clones observed after culture adaptation than at presentation (Table 2).

Drug treatment had variable effects on the isolate populations. Thirty-six hours after drug treatment all parasites for HL1214 had been cleared below the level of detection in the PCR assay. However, all other isolates still had multiple clones persisting in the sample after the first 13-20 hours of drug treatment. For three isolates there was no change in the number of clones detected on Day 1 post-treatment; HL1209 (six clones), HL1210 (four clones) and HL1211 (three clones). For two isolates, HL1204 and HL1205, there was an additional clone detected in vivo at Day 1, as has been previously described for an imported malaria case [47].

\section{Sensitivity to anti-malarial drugs in vitro}

The culture-adapted isolates were all tested for their sensitivity to a range of MMV-supplied anti-malarial agents using a standard 48-hour drug exposure and then measuring viability using the fluorescent PicoGreen method [38]. All the isolates were highly sensitive to the endoperoxides, dihydroartemisinin and OZ277, with $\mathrm{IC}_{50}$ values below $5 \mathrm{nM}$ or $2 \mathrm{nM}$, respectively (Table 3 ). When examining the activity of the 4-aminoquinolines, it was observed that two of the isolates (HL1205 and HL1210) were resistant to chloroquine with $\mathrm{IC}_{50}$ values around $150 \mathrm{nM}$ (chloroquine resistance defined as $\mathrm{IC}_{50}$ value $>100 \mathrm{nM}$ [48]). Interestingly, the histories of these two donors indicate that an incomplete course of 
Table 2 Multiplicity of infection in clinical isolates

\begin{tabular}{|c|c|c|c|c|c|c|c|c|}
\hline \multirow[t]{2}{*}{ Isolate } & \multirow[t]{2}{*}{ Sample } & \multicolumn{3}{|c|}{ pfmsp1 } & \multicolumn{2}{|c|}{ pfmsp2 } & \multicolumn{2}{|c|}{ Minimum number of clones* } \\
\hline & & $\mathrm{K} 1$ & MAD20 & R033 & FC27 & IC & Per sample & Per isolate \\
\hline \multirow[t]{3}{*}{ HL1204 Kenya } & Day 0 pre-treatment & 0 & 1 & 2 & 0 & 1 & 3 & 4 \\
\hline & Day 1 post-treatment & 0 & 2 & 2 & 0 & 1 & 4 & \\
\hline & Culture-adapted & 0 & 1 & 1 & 0 & 1 & 2 & \\
\hline \multirow[t]{3}{*}{ HL1205 Nigeria } & Day 0 pre-treatment & 1 & 0 & 1 & 3 & 1 & 4 & 5 \\
\hline & Day 1 post-treatment & 2 & 0 & 1 & 4 & 1 & 5 & \\
\hline & Culture-adapted & 2 & 0 & 2 & 3 & 1 & 4 & \\
\hline \multirow[t]{3}{*}{ HL1209 South Sudan } & Day 0 pre-treatment & 0 & 2 & 2 & 4 & 2 & 6 & 6 \\
\hline & Day 1 post-treatment & 0 & 1 & 2 & 4 & 2 & 6 & \\
\hline & Culture-adapted & 0 & 2 & 2 & 4 & 2 & 6 & \\
\hline \multirow[t]{3}{*}{ HL1210 Ghana } & Day 0 pre-treatment & 2 & 2 & 0 & 0 & 1 & 4 & 4 \\
\hline & Day 1 post-treatment & 2 & 2 & 0 & 0 & 1 & 4 & \\
\hline & Culture-adapted & 2 & 2 & 0 & 0 & 1 & 4 & \\
\hline \multirow[t]{3}{*}{ HL1211 Ghana } & Day 0 pre-treatment & 2 & 0 & 0 & 0 & 3 & 3 & 6 \\
\hline & Day 1 post-treatment & 2 & 0 & 0 & 0 & 3 & 3 & \\
\hline & Culture-adapted & 1 & 0 & 2 & 4 & 2 & 6 & \\
\hline \multirow[t]{2}{*}{${ }^{\dagger}$ HL1212 Nigeria } & Day 0 pre-treatment & 3 & 2 & 1 & 2 & 1 & 6 & 6 \\
\hline & Culture-adapted & 2 & 1 & 0 & 3 & 1 & 4 & \\
\hline \multirow[t]{3}{*}{ HL1214 Burkina Faso } & Day 0 pre-treatment & 0 & 1 & 1 & 0 & 2 & 2 & 2 \\
\hline & Day 1 post-treatment & 0 & 0 & 0 & 0 & 0 & 0 & \\
\hline & Culture-adapted & 0 & 1 & 1 & 0 & 2 & 2 & \\
\hline
\end{tabular}

*The minimum number of clones in each sample was estimated by adding the highest number of bands for each Pfmsp allele.

${ }^{\dagger}$ No Day 1 post-treatment sample was obtained for HL1212.

chloroquine was probably taken, prior to presentation at HTD, in both cases.

The five remaining isolates were highly sensitive to chloroquine $(<15 \mathrm{nM})$ and all seven isolates were sensitive to amodiaquine and piperaquine with $\mathrm{IC}_{50}$ values below $8 \mathrm{nM}$ or $32 \mathrm{nM}$, respectively (Table 3 ). Sensitivity to desethyl-amodiaquine was not evaluated. Among the arylaminoalcohol class of compounds HL1210 was the most sensitive of the isolates to both mefloquine (7.7 $\mathrm{nM})$ and lumefantrine $(24 \mathrm{nM})$. The $\mathrm{IC}_{50}$ values for mefloquine in the remaining isolates ranged from 17-36 $\mathrm{nM}$. The cut-off for mefloquine resistance has been proposed to be $30 \mathrm{nM} \mathrm{[48]} \mathrm{and} \mathrm{thus} \mathrm{the} \mathrm{HL1209} \mathrm{isolate} \mathrm{could}$ be considered resistant by this definition. However, many of the isolates demonstrate a reduced sensitivity to mefloquine with $\mathrm{IC}_{50}$ values above $20 \mathrm{nM}$. In contrast to the results obtained for the other arylaminoalcohol compounds, isolate HL1210 was the least sensitive to quinine (156 nM) with the $\mathrm{IC}_{50}$ values for the remaining isolates all below 60 $\mathrm{nM}$ (Table 3). For the remaining compounds, all seven isolates were sensitive to pyronaridine, with $\mathrm{IC}_{50}$ values below $4 \mathrm{nM}$, and all highly sensitive to atovaquone with $\mathrm{IC}_{50}$ values below $1 \mathrm{nM}$ (Table 3). Lastly, all but one of the isolates (i e, HL1214, $\mathrm{IC}_{50}$ value $=62 \mathrm{nM}$ ) were highly resistant to the dihydrofolate reductase (DHFR) inhibitor pyrimethamine with $\mathrm{IC}_{50}$ values greater than $10 \mu \mathrm{M}$ (pyrimethamine resistance defined as an $\mathrm{IC}_{50}$ value > $100 \mathrm{nM}$ [48]).

Of particular interest are in vitro responses to lumefantrine, as almost all of the contributing patients received a course of oral artemether-lumefantrine as part of their treatment, and one isolate, HL1211, was obtained from a donor that appeared to have failed treatment on this combination. Apart from HL1210, all isolates exhibited quite low in vitro sensitivity to lumefantrine with $\mathrm{IC}_{50}$ values ranging from $67-119 \mathrm{nM}$, with the cultureadapted line from isolate HL1211 in the middle of this range at $67 \mathrm{nM}$. This line took many weeks to recover to sustainable levels in vitro, and the clonal data in Table 2 suggests that very minor genotypes undetectable in the pre-treatment sample, which was the apparent in vivo treatment failure from the earlier course of artemetherlumefantrine, gradually recovered in abundance to predominate in the adapted line. Separation of the sub-clones in isolate HL1211 may vary in intrinsic lumefantrine sensitivities, which is "averaged" among them in the bulk multiclonal culture, thus obscuring any significant lumefantrine resistant phenotype. It may also be that in vitro estimation of lumefantrine sensitivity is a poor correlate of in vivo treatment response, and to date no validated $\mathrm{IC}_{50}$ 
Table 3 Sensitivity of the Plasmodium falciparum patient isolates to a panel of anti-malarial compounds

\begin{tabular}{|c|c|c|c|c|c|c|c|c|c|c|c|}
\hline \multirow[t]{3}{*}{ Isolate } & \multicolumn{11}{|c|}{$\mathrm{IC}_{50}$ values $(\mathrm{nM})$} \\
\hline & \multicolumn{2}{|c|}{ Endoperoxides } & \multicolumn{3}{|c|}{ 4-aminoquinolines } & \multicolumn{3}{|c|}{ Arylaminoalcohols } & \multicolumn{3}{|c|}{ Other } \\
\hline & DHA & OZ277 & CQ & $A Q$ & PIP & MQ & LUM & QUI & PND & ATV & PYR \\
\hline HL1204 Kenya & $2.7 \pm 0.4$ & $0.5 \pm 0.1$ & $13 \pm 2$ & $3.6 \pm 0.5$ & $27 \pm 4$ & $20 \pm 2$ & $119 \pm 17$ & $42 \pm 10$ & $2.6 \pm 0.5$ & $0.7 \pm 0.1$ & $>10000$ \\
\hline HL1205 Nigeria & $3.6 \pm 0.7$ & $0.5 \pm 0.1$ & $149 \pm 10$ & $5.6 \pm 0.5$ & $21 \pm 4$ & $17 \pm 1$ & $105 \pm 20$ & $58 \pm 7$ & $3.6 \pm 0.9$ & $0.7 \pm 0.1$ & $>10000$ \\
\hline HL1209 South Sudan & $4.7 \pm 0.6$ & $1.5 \pm 0.5$ & $12 \pm 1$ & $6.7 \pm 1.1$ & $26 \pm 3$ & $36 \pm 6$ & $110 \pm 23$ & $60 \pm 7$ & $2.2 \pm 0.8$ & $0.2 \pm 0.03$ & $>10000$ \\
\hline HL1210 Ghana & $1.7 \pm 0.3$ & $1.1 \pm 0.2$ & $150 \pm 7$ & $7.4 \pm 0.5$ & $16 \pm 2$ & $7.7 \pm 0.8$ & $24 \pm 6$ & $156 \pm 17$ & $1.9 \pm 0.5$ & $0.4 \pm 0.1$ & $>10000$ \\
\hline HL1211 Ghana & $4.1 \pm 0.3$ & $1.1 \pm 0.2$ & $12 \pm 1$ & $5.8 \pm 0.8$ & $31 \pm 7$ & $27 \pm 3$ & $67 \pm 18$ & $50 \pm 16$ & $1.7 \pm 0.2$ & $0.3 \pm 0.04$ & $>10000$ \\
\hline HL1212 Nigeria & $3.3 \pm 0.8$ & $0.6 \pm 0.09$ & $12 \pm 3$ & $4.2 \pm 1.2$ & $27 \pm 4$ & $23 \pm 3$ & $91 \pm 21$ & $22 \pm 4$ & $2.6 \pm 0.9$ & $0.8 \pm 0.04$ & $>10000$ \\
\hline HL1214 Burkina Faso & $3.3 \pm 0.7$ & $0.6 \pm 0.07$ & $14 \pm 3$ & $4.2 \pm 0.3$ & $23 \pm 7$ & $23 \pm 1$ & $77 \pm 28$ & $52 \pm 10$ & $1.3 \pm 0.6$ & $0.7 \pm 0.2$ & $62 \pm 25$ \\
\hline \multicolumn{12}{|l|}{ Laboratory strains } \\
\hline 3D7 Netherlands & $5.5 \pm 1.0$ & $1.1 \pm 0.3$ & $15 \pm 2$ & $7.6 \pm 1.7$ & $14 \pm 1$ & $23 \pm 3$ & $73 \pm 22$ & $53 \pm 6$ & $5.0 \pm 0.9$ & $0.3 \pm 0.2$ & $28 \pm 7$ \\
\hline K1 Thailand & $5.2 \pm 0.9$ & $0.8 \pm 0.3$ & $374 \pm 55$ & $10 \pm 3$ & $37 \pm 3$ & $6.8 \pm 2.9$ & $32 \pm 4$ & $289 \pm 40$ & $16 \pm 5$ & $4.3 \pm 1.0$ & $>10000$ \\
\hline
\end{tabular}

The abbreviations for the antimalarial compounds are: dihydroartemisinin (DHA), arterolane, synthetic endoperoxide (OZ277), chloroquine (CQ), amodiaquine (AQ), piperaquine (PIP), mefloquine (MQ), lumefantrine (LUM), quinine (QUI), pyronaridine (PND), atovaquone (ATV) and pyrimethamine (PYR).

The $\mathrm{IC}_{50}$ values are averaged from at least three independent experiments with some repeated on more than ten occasions. All data are presented as mean \pm S.E. $\mathrm{M}$. In several instances, the $\mathrm{IC}_{50}$ values for pyrimethamine exceeded the limits of detection for the concentration range adopted in the experiments and are thus reported as >10,000 nM.

cut-off for adequate lumefantrine sensitivity has been established; all of the contributing patients apart from HL1211 recovered well on artemether-lumefantrine combination therapy, as either sole therapy, or as a follow-on oral regimen after intravenous artesunate.

\section{Genes associated with drug resistance Pfcrt}

Multiplex real-time PCR was used to identify the alleles at the chloroquine resistance transporter ( $p f c r t$ ) codons 72-76 for all the isolates with samples taken on Day 0 (pre-treatment), Day 1 (post-treatment) and after cultureadaptation (Table 4). For both the HL1211 and HL1214 isolates, the wild type CVMNK was the only detectable haplotype in all samples. This haplotype is associated with sensitivity to chloroquine [6] and supports the low chloroquine $\mathrm{IC}_{50}$ values reported for these isolates in Table 3. In the HL1205 and HL1210 isolates, which both exhibited high chloroquine $\mathrm{IC}_{50}$ values, only the chloroquineresistant CVIET haplotype was detected for all samples; as noted above, both isolates are from patients who reported self-medication with tablets that were almost certainly chloroquine. The remaining isolates, HL1204, HL1209 and HL1212 all show a mixed CVMNK/CVIET haplotype on Day 0 and Day 1 (no data for HL1212 on Day 1). However, when these isolates are adapted to grow in culture, only the CQS CVMNK haplotypes are detected. No SVMNT haplotypes, associated with resistance to amodiaquine and chloroquine, were observed in any of the isolates.

\section{Pfmdr1}

The isolates were sequenced to look for polymorphisms in the multidrug resistance gene (pfmdr1) associated with drug resistance: namely, N86Y, Y184F, S1034C, N1042D and D1246Y. No changes were observed from the wild type codons S1034, N1042 and D1246 for any of the isolate samples examined (Table 4). All but one isolate (HL1210; 86Y) harboured the wild type Asn at codon 86. The HL1212 isolate was the only isolate to harbour a mixed haplotype in the pre-treatment sample but only a single haplotype was evident in the HL1212 cultureadapted sample. Real-time PCR analysis of each the samples revealed all the isolates possess only a single copy of the pfindr1 gene (Table 4).

\section{Pfdhps and Pfdhfr}

The isolates were also examined for polymorphisms in the genes associated with resistance to the antifolate drugs. Mutations in the dihydropteroate synthase gene, pfdhps, are responsible for resistance to the anti-malarial sulphadoxine. Important amino acid changes associated with resistance include I431V, S436A, A437G, K540E, A581G and A613S. Only one isolate, HL1209, encoded the wild type amino acids at all six positions in pfdhps (Table 4). Three isolates (i e, HL1210, HL1212 and HL1214) showed a single amino acid change, A437G, while two of the double mutants contained this mutation plus either a K540E (for HL1204) or S436A (for HL1211). Isolate HL1205 was unusual as its two amino acid changes did not include the A437G mutation but instead harboured the mutations S436F and A613S. Furthermore, HL1205 
Table 4 Haplotypes of parasite markers associated with drug resistance

\begin{tabular}{|c|c|c|c|c|c|c|}
\hline \multirow[t]{3}{*}{ Isolate } & \multirow[t]{3}{*}{ Sample } & \multicolumn{5}{|c|}{ Haplotype } \\
\hline & & Pfcrt & Pfmdr1 & Pfdhps & Pfdhfr & Pfmdr1 \\
\hline & & $72-76$ & $86,184,1034,1042,1246$ & $431,436,437,540,581,613$ & $16,50,51,59,108,140,164$ & Gene copy number \\
\hline & Wild type reference & CVMNK & NYSND & ISAKAA & ACNCSVI & \\
\hline \multirow[t]{3}{*}{ HL1204 Kenya } & Day 0 pre-treatment & CVMNK / CVIET & NFSND & ISGEAA & ACNRNVI & 1 \\
\hline & Day 1 post-treatment & CVMNK / CVIET & NFSND & ISGEAA & ACNRNVI & 1 \\
\hline & Culture-adapted & CVMNK & NFSND & ISGEAA & ACNRNVI & 1 \\
\hline \multirow[t]{3}{*}{ HL1205 Nigeria } & Day 0 pre-treatment & CVIET & NYSND & IFAKAS & ACIRNVI & 1 \\
\hline & Day 1 post-treatment & CVIET & NYSND & IFAKAS / ISGKAA & ACIRNVI & 1 \\
\hline & Culture-adapted & CVIET & NYSND & IFAKAS & ACIRNVI & 1 \\
\hline \multirow[t]{3}{*}{ HL1209 South Sudan } & Day 0 pre-treatment & CVMNK / CVIET & NFSND & ISAKAA & ACICNVI & 1 \\
\hline & Day 1 post-treatment & CVMNK / CVIET & NFSND & ISAKAA & ACICNVI & 1 \\
\hline & Culture-adapted & CVMNK & NFSND & ISAKAA & ACICNVI & 1 \\
\hline \multirow[t]{3}{*}{ HL1210 Ghana } & Day 0 pre-treatment & CVIET & YFSND & ISGKAA & ACNRNVI / ACIRNVI & 1 \\
\hline & Day 1 post-treatment & CVIET & YFSND & ISGKAA & ACNRNVI / ACIRNVI & 1 \\
\hline & Culture-adapted & CVIET & YFSND & ISGKAA & ACNRNVI / ACIRNVI & 1 \\
\hline \multirow[t]{3}{*}{ HL1211 Ghana } & Day 0 pre-treatment & CVMNK & NYSND & IAGKAA & ACIRNVI & 1 \\
\hline & Day 1 post-treatment & CVMNK & NYSND & IAGKAA & ACIRNVI & 1 \\
\hline & Culture-adapted & CVMNK & NFSND & ISAKAA & ACICNVI & 1 \\
\hline \multirow[t]{2}{*}{ *HL1212 Nigeria } & Day 0 pre-treatment & CVMNK / CVIET & NYSND / NFSND & ISGKAA & ACIRNVI & 1 \\
\hline & Culture-adapted & CVMNK & NFSND & ISGKAA & ACIRNVI & 1 \\
\hline \multirow[t]{2}{*}{ §HL1214 Burkina Faso } & Day 0 pre-treatment & CVMNK & NFSND & ISGKAA & ACNCSVI / ACNRNVI & 1 \\
\hline & Culture-adapted & CVMNK & NFSND & ISGKAA & ACNCSVI / ACNRNVI & 1 \\
\hline
\end{tabular}

*No Day 1 post-treatment sample was obtained for HL1212.

${ }^{5}$ No haplotype data was obtained for the Day 1 post-treatment sample most likely due to complete parasite clearance shortly after drug administration.

For clarity, wild type haplotypes for each gene reported are highlighted in bold. 
also showed a mixed haplotype in its post-treatment sample, which did include the single mutant A437G (Table 4).

Resistance to pyrimethamine is caused by mutations in the dihydrofolate reductase gene, $p f d h f r$, and is associated with the following amino acid changes: A16V, N51I, C59R, S108N and I164L. The only isolate carrying the pyrimethamine sensitive wild type haplotype was HL1214 (Table 4). All the other isolates harboured pyrimethamine resistance haplotypes and all contained the amino acid change from a serine to asparigine in codon 108 (S108N) which has been suggested to be a vital first step in the development of mutants with higher levels of pyrimethamine resistance [49]. The double mutants carried an additional mutation, changing either an asparigine to isoleucine at codon 51 (N51I - HL1209) or a cysteine to arginine at codon 59 (C59R -HL1204, HL1210, HL1214). The triple mutants contained mutations in all three aforementioned codons (i e, N51I, C59R and S108N). No mutations were observed in the amino acids at codons 16, 50, 140 and 146, which have also been implicated in resistance to pyrimethamine and/or cycloguanil [43,50]. Interestingly, within each isolate, none of the pfdhfr haplotypes varied among the pre-treatment, post-treatment or culture-adapted samples.

\section{Pfap2-mu}

Sequences for this gene were determined for all available ex vivo and in vitro parasite preparations. None of the previously described non-synonymous polymorphisms at codons 146, 160, 199, 233 or 437 of pfap $2 m u$ were found in any parasite line, or in any ex vivo parasite DNA sample. Some variation was observed in the previously described poly-Asn tracts which occur between codons 226 and 234, and between codons 326 and 331 [36]. A synonymous mutation from A to $\mathrm{G}$ at the third position of codon 163 (Glu) was present in HL1209, HL1211 and HL1214, usually as a mixture of both alleles. However, in HL1211 all ex vivo parasite isolates carried the GAA form of codon 163 , whereas the culture-adapted parasite line appeared to harbour only GAG alleles.

\section{Discussion}

Using the Methods in Malaria Research protocol for culturing new isolates [45], it was possible to successfully adapt all seven of the African P. falciparum patient isolates to in vitro conditions. The parasites grew more readily in the combination of $0.5 \% \mathrm{w} / \mathrm{v}$ Albumax II with $2 \%$ human $\mathrm{AB}$ serum when compared with the HL1204 line initially grown in $10 \%$ human $\mathrm{AB}$ serum in the absence of Albumax II.

The African isolates in this study were shown to be composed of a complex mixture of parasites with a minimum of between two and six clones. This level of complexity is similar to that reported by Robinson et al. [46]. In that study also, patients presenting with malaria to HTD after travel to Africa were assessed for MOI and found to harbour complex mixtures of between three and five clones using both $m s p 1$ and $m s p 2$ genotyping and whole genome analysis [46]. Differences in pfmsp1 and pfmsp 2 repertoires were noted between ex vivo isolates analysed directly, and those from cultures established from the same sample over time, most notably for HL1211 (Table 2). This can be explained by the stochastic variation seen in PCR amplification of complex mixtures [50], and the fact that ex vivo PCR was performed on the equivalent of $10 \mu \mathrm{L}$ of peripheral blood, whereas at least 100 times that volume of blood was used to establish each long-term culture, and this could easily have harboured additional genotypes. Examining clonality through PCR amplification of the $m s p 1$ and $m s p 2$ loci is subject to error and can only provide a minimum estimate of MOI [51]. How then does this observed genetic complexity arise? Polyclonality need not arise from multiple mosquito bites and can result from a single sporozoite inoculation, as suggested by studies of infections in travellers with minimal exposure to infective bites [46,47]. This genetic complexity in African isolates represents an important difference from those obtained from other regions, thereby emphasizing the potential benefit of establishing multiclonal isolates for in vitro studies as a more accurate model of the African $P$. falciparum infections found in the field. When the culture-adapted parasites were compared with the original "pre-treatment" source parasites it was found that in four of the seven isolates, the number of clones detected remained unchanged after adaptation. Despite the loss of one and two clones in culture-adapted HL1204 and HL1212, respectively, the data in Table 2 suggest that the culture conditions adopted are favourable to support the growth of multiple clones and that these isolates should therefore maintain their genetic complexity over time.

All the patients in this study were treated with ACT therapy which consists of a rapid-acting artemisinin-based compound (artemether) co-formulated with a longeracting compound (lumefantrine), although in two cases this oral regimen followed initial treatment with intravenous artesunate. In only one of the patients (the donor of HL1214) were the parasites cleared completely within 24 hours of the treatment administration below the detection level of the nested PCR assay. In the remaining isolates multiple clones remained detectable after treatment, and in two of the samples (HL1204, HL1205) the number of parasite clones detected had increased by one compared with the number observed pre-treatment. Such complicated clonal dynamics during treatment do not imply that parasites are resistant to anti-malarial agents, but are due to fluctuations in relative clonal densities which frequently occur in treated patients [47]. Clones present in the pretreatment sample at low density relative to other wellrepresented clones in the overall parasite population may not be amplified sufficiently to enable detection. However, 
one day post-treatment, with the parasite load decreased after the drug administration, these clones may become more evident using the nested PCR method.

\section{Drug sensitivity/resistance}

The WHO-recommended combination therapy approach was intended to prevent parasites from developing resistance to the rapid-acting, highly potent but quickly eliminated artemisinin derivatives. All the isolates in this study were shown to be highly sensitive to dihydroartemisinin and the synthetic endoperoxide, OZ277. Recently, reports have emerged of artemisinin resistance characterized by a "delayed clearance" phenotype in Thailand, Cambodia and Myanmar [28,30-34]. A conventional 48-hour drug exposure assay was used to assess parasite growth in this study. Under similar in vitro assay conditions, previous studies have been unable to detect artemisinin tolerant parasites, and new assays have been proposed that use a short pulse exposure to the artemisinin derivative DHA [34,52]. Although it is of interest to screen the isolates presented here with such assays, a "delayed clearance" phenotype similar to that seen in Southeast Asia has not yet been reported in African studies of ACT efficacy in the field.

Most of the culture-adapted isolates (five out of seven) were sensitive to chloroquine (Table 3), and all five harboured the CVMNK haplotype at codons 72-76 of pfcrt (Table 4). A recent study has shown that treatment with the ACT artemether-lumefantrine (Coartem ${ }^{\circ}$ ) leads to the selection of parasites with the lysine at codon 76 in Tanzanian parasites [53]. The two CQR isolates were both confirmed to harbour the CVIET haplotype commonly found in Africa and Asia [54]. In countries where amodiaquine was used as first-line monotherapy for malaria, the predominant CQR haplotype emerging has been SVMNT [55]. In Africa however, chloroquine was preferred to amodiaquine and, not surprisingly, the SVMNT CQR haplotype found mostly in Asia, South America and Papua New Guinea was not observed in these African isolates. Although the CVIET haplotype in the mixed CVMNK/CVIET pre-treatment isolates (i e, HL1204, HL1209 and HL1212: Table 4) was not detected in the culture-adapted isolates, these clones may still be present but below the level of sensitivity of the assay. Using chloroquine drug pressure it may be possible to select for these minor clones in vitro in the culture-adapted lines. The reason for these CQR clones not thriving from the mixed CVMNK/CVIET pre-treatment parasites into culture adaptation may be related to a fitness cost associated with mutations in the CQR genes, pfcrt and pfmdr1 [56].

Mutations in the pfmdrl gene have been implicated in modulating the sensitivity to several classes of anti-malarial agents including the 4-aminoquinolines, arylaminoalcohols and endoperoxides [57-59]. Three haplotypes representing the five codons implicated previously in drug resistance (i e,
$86,184,1034,1042$, and 1246) were identified among the HL isolates. These were NYSND (wild type), NFSND and YFSND. While sensitivity to chloroquine has been shown to be mediated by mutations in both pfcrt and pfmdr1 $[6,7,58]$, the chloroquine $\mathrm{IC}_{50}$ values reported here do not correlate with any particular pfmdr1 haplotype. Examining the $p f c r t$ haplotype in these isolates is sufficient to predict accurately the chloroquine sensitivity for these isolates irrespective of changes in pfmdr1.

As with chloroquine, sensitivity to the anti-malarial quinine has been shown to be modulated by mutations in both the pfcrt and pfmdr1 genes [58-60]. In contrast to chloroquine though, the sensitivity to quinine in these isolates cannot be explained by its pfcrt haplotype alone. On the other hand, the one isolate showing a reduced sensitivity to quinine (HL1210; $\mathrm{IC}_{50}$ value $\geq 2.5$-fold relative to all other isolates) was shown to be the only one harbouring the YFSND haplotype in pfmdr1. This haplotype differs from the two other $p f m d r 1$ haplotypes observed in the isolates by the presence of Tyr encoded at codon 86. Similarly, the YFSND haplotype found in HL1210 results in the greatest sensitivity to mefloquine and lumefantrine. All the remaining isolates with the Asn at codon 86 were less sensitive to mefloquine and lumefantrine (all $>2$-fold $\mathrm{IC}_{50}$ value relative to HL1210). The prominence of the Asn observed at codon 86 in these isolates is not surprising. A previous in vitro study showed that parasites of this genotype were less sensitive to arylaminoalcohol compounds (e g, mefloquine, lumefantrine) and endoperoxides (e g, artemisinin) [57]. This might imply that in order to evade the toxicity of these compounds in vivo, parasites carrying the asparigine at codon 86 would be selected in place of those carrying the tyrosine. Indeed, several studies have confirmed this concerning trend. In several African countries where Coartem $^{\circ}$ has been used as first-line treatment for uncomplicated $P$. falciparum malaria, reports have emerged that the N86 codon of pfmdr1 is being selected $[35,42,61,62]$. Furthermore, Mwai et al. reported that parasites harbouring both the K76 in pfcrt and N86 in pfmdr1 had higher lumefantrine $\mathrm{IC}_{50}$ values than those with mutant alleles [63]. This N86 selection then could explain the high mefloquine and lumefantrine $\mathrm{IC}_{50}$ values reported in these isolates while the Y86 found in HL1210 is consistent with sensitivity to these compounds.

Multiple copies of the pfmdr1 gene have been linked to reduced susceptibility to lumefantrine in vitro in Thai isolates [64]. However, in the limited number of African isolates reported here, no increases in pfmdr1 copy number were observed irrespective of their susceptibility to lumefantrine. This does not rule out a role for $p f m d r 1$ copy number in reduced drug susceptibility in Africa although as it has been observed recently in Sudanese malaria patients that pfmdr1 amplification was linked to recurrent infection after treatment with artemether- 
lumefantrine [35]. For the pfap2mu locus, only minor variation in the length of Asn-rich tracts was observed in the isolates examined. In HL1211 an allele with a variant codon 163 appeared to be selected in the established culture line, but this is a synonymous change and is unlikely to have any direct bearing on drug response.

Pyronaridine, a compound currently in Phase IV clinical trials as a licensed combination therapy with artesunate $\left(\right.$ Pyramax $\left.^{\circ}\right)$, is highly potent against all isolates in this study irrespective of their resistance to chloroquine and pyrimethamine and altered sensitivity to the arylaminoalcohol compounds. Previous studies have proposed that CQR strains exhibit cross-resistance to pyronaridine [65] but recent evidence suggests that pyronaridine remains effective against CQR strains [66]. The results from the small sample of isolates provided here suggest that pyronaridine would be an effective treatment against multiclonal African parasites of diverse origin and drug-resistance profiles. Furthermore, the naphthoquinone atovaquone which is marketed as a fixed combination with proguanil (Malarone), and widely used for chemoprophylaxis by travellers to malariaendemic regions, was highly potent against all the isolates tested in this study.

The high degree of resistance to the dihydrofolate reductase inhibitor pyrimethamine in all but one of the isolates (i e, HL1214) probably reflects the widespread use of the antifolate therapy Fansidar (sulphadoxine/pyrimethamine) as first-line anti-malarial treatment across Africa for many years preceding the $\mathrm{WHO}$ recommendation for using $\mathrm{ACT}$ as first-line treatment. The $\mathrm{IC}_{50}$ values presented for pyrimethamine (Table 3) are supported by the DHFR haplotypes reported for each isolate in Table 4. As predicted from its sensitivity to pyrimethamine (62 nM; Table 3), HL1214 was the only isolate with the wild type 3D7-like haplotype. Interestingly, a resistant haplotype was also detected for this isolate suggesting that these parasites are present probably as a minor population within the isolate given that there was no effect on increasing the $\mathrm{IC}_{50}$ value beyond the $100 \mathrm{nM}$ cut-off for resistance. All of the other resistant isolates contained either a double or triple mutation in pfdhfr that would be expected to result in a "moderate" or "high" level of pyrimethamine resistance, respectively $[48,49,67]$. All the resistant isolates harboured the change from a serine to asparigine in codon 108 (S108N) which has been suggested to be a critical first step in the development of mutants with higher levels of pyrimethamine resistance [49]. The double mutants carried an additional mutation, changing either an asparigine to isoleucine at codon 51 (N51I - eg., HL1209) or a cysteine to arginine at codon 59 (C59R - e g, HL1204, HL1210, HL1214) which are expected to result in moderate resistance to pyrimethamine, whereas parasites with mutations at all three codons (i e, N51I, C59R and S108N) are expected to display high level pyrimethamine resistance [49]. No mutations were observed in the amino acids at positions 16, 50, 140 and 164, which have also been implicated in resistance to pyrimethamine and/or cycloguanil $[43,49]$.

The anti-malarial agent sulphadoxine, a drug used in combination with pyrimethamine in the drug treatment Fansidar, was not included in the panel of compounds tested in this study. However, the dihydropteroate synthase gene (pfdhps) was sequenced to look for mutations associated with sulphadoxine resistance. All but one (i e, HL1209) of the isolates contained parasites with the A437G amino acid change. This polymorphism, alone or in combination with other mutations in pfdhps, predominates in resistant field isolates [68]. When the A437G mutant is combined with the K540E mutation, this double mutant is strongly associated with clinical Fansidar treatment failure [69]. Interestingly, the HL1209 isolate harbours the "sulphadoxine sensitive" pfdhps haplotype (ISAKAA) but was shown to be carry resistant alleles for pfdhfr. It has been proposed previously that mutations in pfdhps occur only once the parasites in the population carry at least a double mutant allele in $p f d h f r$ [68]. Quintuple mutants with two mutations in pfdhps (A437G, K540E) and three mutations in pfdhfr (N51I, C59R, S108N) are strongly associated with Fansidar treatment failure [69]. Isolates HL1205 and HL1211 both carry the requisite triple mutations in pfdhfr and harbour double mutations in pfdhps but these double mutations in pfdhps differ from those previously linked with treatment failure. It is unclear whether these quintuple mutant variants are as likely to result in clinical failure after Fansidar treatment.

\section{Conclusions}

This study describes the establishment in continuous culture, in vitro drug sensitivity testing and molecular characterization of a series of multiclonal $P$. falciparum isolates taken directly from UK malaria patients following recent travel to various malaria-endemic countries in Africa. These "HL" isolates are available as an open resource for studies of drug response, antigenic diversity and other aspects of parasite biology.

\section{Additional file}

Additional file 1: Primer sequences and annealing conditions for candidate gene amplification.

\section{Competing interests}

The authors declare that they have no competing interests.

\section{Authors' contributions}

CJS and DAvS conceived and designed the study, with input from RB and XCD. CJS, CH, SGW and PLC interviewed patients and collated clinical data. $\mathrm{RB}, \mathrm{DAvS}, \mathrm{GH}, \mathrm{KBB}$ and NG performed the experiments. XCD supplied the anti-malarial compounds and provided comments on the manuscript. DAvS, RB and CJS analysed the data and wrote the paper. All authors read and approved the final manuscript. 


\section{Acknowledgments}

Eloise Thompson is thanked for technical advice and logistical support. The contributing patients and their families are thanked for their patience and unselfish cooperation. This research was supported by the Medicines for Malaria Venture. CJS is supported by Public Health England. KBB is supported by the EDCTP WANECAM Consortium coordinated by Prof. A. Djimde. PLC is supported by the UCL Hospitals Comprehensive Biomedical Research Centre Infection Theme.

\section{Author details}

${ }^{1}$ Faculty of Infectious and Tropical Diseases, London School of Hygiene and Tropical Medicine, Keppel Street, London WC1E 7HT, UK. ${ }^{2}$ Department for Acute Medicine and Chest Medicine, University College London Hospitals, London NW1 2PG, UK. ${ }^{3}$ Department of Clinical Parasitology, Hospital for Tropical Diseases, Mortimer Market Centre, Capper Street, London WC1E 6JB, UK. ${ }^{4}$ Medicines for Malaria Venture, 20 rte de Pré Bois, Geneva CH 1215, Switzerland.

Received: 8 July 2013 Accepted: 10 September 2013

Published: 13 September 2013

\section{References}

1. Sutherland CJ, Tanomsing N, Nolder D, Oguike M, Jennison C, Pukrittayakamee S, Dolecek C, Hien TT, do Rosário VE, Arez AP, Pinto J, Michon P, Escalante AA, Nosten F, Burke M, Lee R, Blaze M, Otto TD, Barnwell JW, Pain A, Williams J, White NJ, Day NP, Snounou G, Lockhart PJ, Chiodini PL, Imwong M, Polley SD: Two nonrecombining sympatric forms of the human malaria parasite Plasmodium ovale occur globally. J Infect Dis 2010, 201:1544-1550

2. Singh B, Kim Sung L, Matusop A, Radhakrishnan A, Shamsul SS, CoxSingh J, Thomas A, Conway DJ: A large focus of naturally acquired Plasmodium knowlesi infections in human beings. Lancet 2004, 363:1017-1024

3. Trager W, Jensen JB: Human malaria parasites in continuous culture. Science 1976, 193:673-675.

4. Molina-Cruz A, DeJong RJ, Ortega C, Haile A, Abban E, Rodrigues J, Jaramillo-Gutierrez G, Barillas-Mury C: Some strains of Plasmodium falciparum, a human malaria parasite, evade the complement-like system of Anopheles gambiae mosquitoes. Proc Natl Acad Sci USA 2012, 109:E1957-E1962.

5. Gaur D, Storry JR, Reid ME, Barnwell JW, Miller LH: Plasmodium falciparum is able to invade erythrocytes through a trypsin-resistant pathway independent of glycophorin B. Infect Immun 2003, 71:6742-6746.

6. Fidock DA, Nomura T, Talley AK, Cooper RA, Dzekunov SM, Ferdig MT, Ursos LM, Sidhu AB, Naude B, Deitsch KW, Su XZ, Wootton JC, Roepe PD, Wellems TE: Mutations in the $P$. falciparum digestive vacuole transmembrane protein PfCRT and evidence for their role in chloroquine resistance. Mol Cell 2000, 6:861-871

7. Foote SJ, Kyle DE, Martin RK, Oduola AM, Forsyth K, Kemp DJ, Cowman AF: Several alleles of the multidrug-resistance gene are closely linked to chloroquine resistance in Plasmodium falciparum. Nature 1990, 345:255-258.

8. WHO: World Malaria Report; 2011. http://www.who.int/malaria/ world_malaria_report_2011/en/.

9. de Delemarre-van Waal HA, de Waal FC: A 2d patient with tropical malaria contracted in a natural way in the Netherlands. Ned Tijdschr Geneeskd $1981,125: 375-377$.

10. Ponnudurai T, Leeuwenberg AD, Meuwissen JH: Chloroquine sensitivity of isolates of Plasmodium falciparum adapted to in vitro culture. Trop Geogr Med 1981, 33:50-54.

11. Walliker D, Quakyi IA, Wellems TE, McCutchan TF, Szarfman A, London WT, Corcoran LM, Burkot TR, Carter R: Genetic analysis of the human malaria parasite Plasmodium falciparum. Science 1987, 236:1661-1666.

12. Anders RF, Brown GV, Edwards A: Characterization of an $\mathrm{S}$ antigen synthesized by several isolates of Plasmodium falciparum. Proc Natl Acad Sci U S A 1983, 80:6652-6656.

13. Bhasin VK, Trager W: Gametocyte-forming and non-gametocyte-forming clones of Plasmodium falciparum. Am J Trop Med Hyg 1984, 33:534-537.

14. Oduola AM, Weatherly NF, Bowdre JH, Desjardins RE: Plasmodium falciparum: cloning by single-erythrocyte micromanipulation and heterogeneity in vitro. Exp Parasitol 1988, 66:86-95.
15. Rosario V: Cloning of naturally occurring mixed infections of malaria parasites. Science 1981, 212:1037-1038.

16. Thaithong S, Beale GH, Fenton B, McBride J, Rosario V, Walker A, Walliker D: Clonal diversity in a single isolate of the malaria parasite Plasmodium falciparum. Trans R Soc Trop Med Hyg 1984, 78:242-245.

17. Sullivan JS, Sullivan JJ, Williams A, Grady KK, Bounngaseng A, Huber CS, Nace D, Williams T, Galland GG, Barnwell JW, Collins WE: Adaptation of a strain of Plasmodium falciparum from Ghana to Aotus lemurinus griseimembra, A. nancymai, and A. vociferans monkeys. Am J Trop Med Hyg 2003, 69:593-600.

18. Udeinya IJ, Graves PM, Carter R, Aikawa M, Miller LH: Plasmodium falciparum: effect of time in continuous culture on binding to human endothelial cells and amelanotic melanoma cells. Exp Parasitol 1983, 56:207-214

19. Thaithong S, Beale GH: Resistance of ten Thai isolates of Plasmodium falciparum to chloroquine and pyrimethamine by in vitro tests. Trans $R$ Soc Trop Med Hyg 1981, 75:271-273.

20. Jensen JB, Capps TC, Carlin JM: Clinical drug-resistant falciparum malaria acquired from cultured parasites. Am J Trop Med Hyg 1981, 30:523-525.

21. Oduola AM, Milhous WK, Weatherly NF, Bowdre JH, Desjardins RE: Plasmodium falciparum: induction of resistance to mefloquine in cloned strains by continuous drug exposure in vitro. Exp Parasitol 1988, 67:354-360.

22. Wellems TE, Oduola AMJ, Fenton B, Desjardins R, Panton LJ, do Rosario VE: Chromosome size variation occurs in cloned Plasmodium falciparum on in vitro cultivation. Rev Bras Genét 1988, 11:813-825.

23. Burkot TR, Williams JL, Schneider I: Infectivity to mosquitoes of Plasmodium falciparum clones grown in vitro from the same isolate. Trans R Soc Trop Med Hyg 1984, 78:339-341.

24. Peterson DS, Milhous WK, Wellems TE: Molecular basis of differential resistance to cycloguanil and pyrimethamine in Plasmodium falciparum malaria. Proc Natl Acad Sci U S A 1990, 87:3018-3022.

25. DeGowin RL, Powell RD: Drug resistance of a strain of P.falciparum from Malaya. Am J Trop Med Hyg 1965, 14:519-528.

26. WHO: Antimalarial drug combination therapy. Report of a WHO technical consultation. [http://www.who.int/malaria/publications/atoz/ who_cds_rbm_2001_35/en/index.html]

27. Makanga M, Krudsood S: The clinical efficacy of artemether/lumefantrine (Coartem). Malar J 2009, 8(Suppl 1):S5.

28. Noedl H, Se Y, Schaecher K, Smith BL, Socheat D, Fukuda MM: Evidence of artemisinin-resistant malaria in western Cambodia. N Engl J Med 2008, 359:2619-2620.

29. Dondorp AM, Nosten F, Yi P, Das D, Phyo AP, Tarning J, Lwin KM, Ariey F, Hanpithakpong W, Lee SJ, Ringwald P, Silamut K, Imwong M, Chotivanich K, Lim P, Herdman T, An SS, Yeung S, Singhasivanon P, Day NP, Lindegardh N, Socheat $D$, White NJ: Artemisinin resistance in Plasmodium falciparum malaria. N Engl J Med 2009, 361:455-467.

30. Amaratunga C, Sreng S, Suon S, Phelps ES, Stepniewska K, Lim P, Zhou C, Mao S, Anderson JM, Lindegardh N, Jiang H, Song J, Su XZ, White NJ, Dondorp AM, Anderson TJ, Fay MP, Mu J, Duong S, Fairhurst RM: Artemisinin-resistant Plasmodium falciparum in Pursat province, western Cambodia: a parasite clearance rate study. Lancet Infect Dis 2012, 12:851-858.

31. Phyo AP, Nkhoma S, Stepniewska K, Ashley EA, Nair S, McGready R, ler Moo C, Al-Saai S, Dondorp AM, Lwin KM, Singhasivanon P, Day NP, White NJ, Anderson TJ, Nosten F: Emergence of artemisinin-resistant malaria on the western border of Thailand: a longitudinal study. Lancet 2012, 379:1960-1966.

32. Kyaw MP, Nyunt MH, Chit K, Aye MM, Aye KH, Lindegardh N, Tarning J, Imwong M, Jacob CG, Rasmussen C, Perin J, Ringwald P, Nyunt MM: Reduced susceptibility of Plasmodium falciparum to artesunate in southern Myanmar. PLoS One 2013, 8:e57689.

33. Teuscher F, Gatton ML, Chen N, Peters J, Kyle DE, Cheng Q: Artemisinininduced dormancy in Plasmodium falciparum: duration, recovery rates, and implications in treatment failure. J Infect Dis 2010, 202:1362-1368

34. Witkowski B, Khim N, Chim P, Kim S, Ke S, Kloeung N, Chy S, Duong S, Leang R, Ringwald P, Dondorp AM, Tripura R, Benoit-Vical F, Berry A, Gorgette O, Ariey F, Barale JC, Mercereau-Puijalon O, Menard D: Reduced artemisinin susceptibility of Plasmodium falciparum ring stages in Western Cambodia. Antimicrob Agents Chemother 2013, 57:914-923. 
35. Gadalla NB, Adam I, Elzaki SE, Bashir S, Mukhtar I, Oguike M, Gadalla A, Mansour F, Warhurst D, El-Sayed BB, Sutherland C: Increased pfmdr1 copy number and sequence polymorphisms in Plasmodium falciparum isolates from Sudanese malaria patients treated with artemether-lumefantrine. Antimicr Agents Chemother 2011, 55:5408-5411.

36. Henriques G, Martinelli A, Rodrigues L, Modrzynska K, Fawcett R, Houston DR, Borges ST, d' Alessandro U, Tinto H, Karema C, Hunt P, Cravo P: Artemisinin resistance in rodent malaria - mutation in the AP2 adaptor mu-chain suggests involvement of endocytosis and membrane protein trafficking. Malar J 2013, 12:118.

37. The European Malaria Reagent Repository. http://www.malariaresearch.eu/.

38. Corbett Y, Herrera L, Gonzalez J, Cubilla L, Capson TL, Coley PD, Kursar TA, Romero LI, Ortega-Barria E: A novel DNA-based microfluorimetric method to evaluate antimalarial drug activity. Am J Trop Med Hyg 2004, 70:119-124.

39. Snounou G, Zhu X, Siripoon N, Jarra W, Thaithong S, Brown KN, Viriyakosol S: Biased distribution of msp1 and msp2 allelic variants in Plasmodium falciparum populations in Thailand. Trans R Soc Trop Med Hyg 1999, 93:369-374.

40. Gadalla NB, Elzaki SE, Mukhtar E, Warhurst DC, El-Sayed B, Sutherland CJ: Dynamics of pfcrt alleles CVMNK and CVIET in chloroquine-treated Sudanese patients infected with Plasmodium falciparum. Malar J 2010, 9:74.

41. Sutherland CJ, Haustein T, Gadalla N, Armstrong M, Doherty JF, Chiodini PL: Chloroquine-resistant Plasmodium falciparum infections among UK travellers returning with malaria after chloroquine prophylaxis. J Antimicrob Chemother 2007, 59:1197-1199.

42. Humphreys GS, Merinopoulos I, Ahmed J, Whitty CJ, Mutabingwa TK, Sutherland CJ, Hallett RL: Amodiaquine and artemether-lumefantrine select distinct alleles of the Plasmodium falciparum mdr1 gene in Tanzanian children treated for uncomplicated malaria. Antimicrob Agents Chemother 2007, 51:991-997.

43. Pearce RJ, Drakeley C, Chandramohan D, Mosha F, Roper C: Molecular determination of point mutation haplotypes in the dihydrofolate reductase and dihydropteroate synthase of Plasmodium falciparum in three districts of northern Tanzania. Antimicrob Agents Chemother 2003, 47:1347-1354

44. Sutherland CJ, Fifer H, Pearce RJ, bin Reza F, Nicholas M, Haustein T, Njimgye-Tekumafor NE, Doherty JF, Gothard P, Polley SD, Chiodini PL: Novel pfdhps haplotypes among imported cases of Plasmodium falciparum malaria in the United Kingdom. Antimicrob Agents Chemother 2009, 53:3405-3410.

45. Moll K, Ljungstrom I, Perlmann H, Scherf A, Wahlgren M: Methods in Malaria Research. Update version 5.2; 2009. http://www.mr4.org/ Publications/MethodsinMalariaResearch.aspx.

46. Robinson T, Campino SG, Auburn S, Assefa SA, Polley SD, Manske M, Maclnnis B, Rockett KA, Maslen GL, Sanders M, Quail MA, Chiodini PL, Kwiatkowski DP, Clark TG, Sutherland CJ: Drug-resistant genotypes and multi-clonality in Plasmodium falciparum analysed by direct genome sequencing from peripheral blood of malaria patients. PLoS One 2011, 6:e23204.

47. Rodger A, Cooke GS, Ord R, Sutherland CJ, Pasvol G: Synchronised cluster of falciparum malaria cases in an airport departure lounge. Emerging Infect Dis 2008, 14:1284-1286.

48. Ringwald P, Bickii J, Basco LK: In vitro activity of antimalarials against clinical isolates of Plasmodium falciparum in Yaounde, Cameroon. Am J Trop Med Hyg 1996, 55:254-258.

49. Sirawaraporn W: Dihydrofolate reductase and antifolate resistance in malaria. Drug Resist Updat 1998, 1:397-406.

50. Beshir KB, Sutherland CJ, Sawa P, Drakeley CJ, Okell L, Mweresa CK, Omar SA, Shekalaghe SA, Kaur H, Ndaro A, Chilongola J, Schallig HD, Sauerwein RW, Hallett RL, Bousema T: Residual Plasmodium falciparum parasitaemia in Kenyan children after artemisinin-combination therapy is associated with increased transmission to mosquitoes and parasite recurrence. $J$ Infect Dis. in press.

51. Juliano JJ, Gadalla N, Sutherland CJ, Meshnick SR: The perils of PCR: can we accurately 'correct' antimalarial trials? Trends Parasitol 2010, 26:119-124

52. Klonis N, Xie SC, MCCaw JM, Crespo-Ortiz MP, Zaloumis SG, Simpson JA, Tilley L: Altered temporal response of malaria parasites determines differential sensitivity to artemisinin. Proc Natl Acad Sci USA 2013, 110:5157-5162.
53. Sisowath C, Petersen I, Veiga MI, Martensson A, Premji Z, Bjorkman A, Fidock DA, Gil JP: In vivo selection of Plasmodium falciparum parasites carrying the chloroquine-susceptible pfcrt K76 allele after treatment with artemether-lumefantrine in Africa. J Infect Dis 2009, 199:750-757.

54. Wootton JC, Feng X, Ferdig MT, Cooper RA, Mu J, Baruch DI, Magill AJ, Su $X Z$ : Genetic diversity and chloroquine selective sweeps in Plasmodium falciparum. Nature 2002, 418:320-323.

55. Sa JM, Twu O, Hayton K, Reyes S, Fay MP, Ringwald P, Wellems TE: Geographic patterns of Plasmodium falciparum drug resistance distinguished by differential responses to amodiaquine and chloroquine. Proc Natl Acad Sci U S A 2009, 106:18883-18889.

56. Ord R, Alexander N, Dunyo S, Hallett R, Jawara M, Targett G, Drakeley CJ, Sutherland CJ: Seasonal carriage of pfort and pfmdr1 alleles in Gambian Plasmodium falciparum imply reduced fitness of chloroquine-resistant parasites. J Infect Dis 2007, 196:1613-1619.

57. Duraisingh MT, Roper C, Walliker D, Warhurst DC: Increased sensitivity to the antimalarials mefloquine and artemisinin is conferred by mutations in the pfmdr1 gene of Plasmodium falciparum. Mol Microbiol 2000, 36:955-961.

58. Reed MB, Saliba KJ, Caruana SR, Kirk K, Cowman AF: Pgh1 modulates sensitivity and resistance to multiple antimalarials in Plasmodium falciparum. Nature 2000, 403:906-909.

59. Sidhu $A B$, Valderramos SG, Fidock DA: pfmdr1 mutations contribute to quinine resistance and enhance mefloquine and artemisinin sensitivity in Plasmodium falciparum. Mol Microbiol 2005, 57:913-926.

60. Cooper RA, Ferdig MT, Su XZ, Ursos LM, Mu J, Nomura T, Fujioka H, Fidock DA, Roepe PD, Wellems TE: Alternative mutations at position 76 of the vacuolar transmembrane protein PfCRT are associated with chloroquine resistance and unique stereospecific quinine and quinidine responses in Plasmodium falciparum. Mol Pharmacol 2002, 61:35-42.

61. Sisowath C, Stromberg J, Martensson A, Msellem M, Obondo C, Bjorkman A, Gil JP: In vivo selection of Plasmodium falciparum pfmdr1 $86 \mathrm{~N}$ coding alleles by artemether-lumefantrine (Coartem). J Infect Dis 2005, 191:1014-1017.

62. Baliraine FN, Rosenthal PJ: Prolonged selection of pfmdr1 polymorphisms after treatment of falciparum malaria with artemether-lumefantrine in Uganda. J Infect Dis 2011, 204:1120-1124.

63. Mwai L, Kiara SM, Abdirahman A, Pole L, Rippert A, Diriye A, Bull P, Marsh K, Borrmann S, Nzila A: In vitro activities of piperaquine, lumefantrine, and dihydroartemisinin in Kenyan Plasmodium falciparum isolates and polymorphisms in pfcrt and pfmdr1. Antimicrob Agents Chemother 2009, 53:5069-5073.

64. Mungthin M, Suwandittakul N, Chaijaroenkul W, Rungsrihirunrat K, Harnyuttanakorn P, Seugorn A, Na Bangchang K: The patterns of mutation and amplification of Plasmodium falciparum pfort and pfmdr1 genes in Thailand during the year 1988 to 2003. Parasitol Res 2010, 107:539-45.

65. Elueze El, Croft SL, Warhurst DC: Activity of pyronaridine and mepacrine against twelve strains of Plasmodium falciparum in vitro. J Antimicrob Chemother 1996, 37:511-518.

66. Pradines B, Briolant S, Henry M, Oeuvray C, Baret E, Amalvict R, Didillon E, Rogier $C$ : Absence of association between pyronaridine in vitro responses and polymorphisms in genes involved in quinoline resistance in Plasmodium falciparum. Malar J 2010, 9:339.

67. Foote SJ, Galatis D, Cowman AF: Amino acids in the dihydrofolate reductase-thymidylate synthase gene of Plasmodium falciparum involved in cycloguanil resistance differ from those involved in pyrimethamine resistance. Proc Natl Acad Sci U S A 1990, 87:3014-3017.

68. Sibley CH, Hyde JE, Sims PF, Plowe CV, Kublin JG, Mberu EK, Cowman AF, Winstanley PA, Watkins WM, Nzila AM: Pyrimethamine-sulfadoxine resistance in Plasmodium falciparum: what next? Trends Parasitol 2001, 17:582-588.

69. Happi CT, Gbotosho GO, Folarin OA, Akinboye DO, Yusuf BO, Ebong OO, Sowunmi A, Kyle DE, Milhous W, Wirth DF, Oduola AM: Polymorphisms in Plasmodium falciparum dhfr and dhps genes and age related in vivo sulfadoxine-pyrimethamine resistance in malaria-infected patients from Nigeria. Acta Trop 2005, 95:183-193.

\section{doi:10.1186/1475-2875-12-320}

Cite this article as: van Schalkwyk et al:: Culture-adapted Plasmodium falciparum isolates from UK travellers: in vitro drug sensitivity, clonality and drug resistance markers. Malaria Journal 2013 12:320. 